\title{
Almost 9: A Personal Essay on Parenting, Aniridia, and Being a Doctor
}

\author{
Nancy C. Elder, MD, MSPH
}

The author, a family physician, writes about her adoptive daughter being diagnosed with the rare genetic disorder aniridia and later with a central auditory processing disorder. Both mother and daughter learn about these disorders and develop coping strategies. (J Am Board Fam Med 2007;20:606-607.)

Even at almost 9 years old, my daughter's hands and wrists are small and waiflike. When she reaches up to hold my hand or grabs onto the hem of my shirt or jacket, I feel her soft, small fingers and automatically stroke them. She gives me the big smile of a little girl with 2 big grown-up front teeth set off by empty holes on either side from recent offerings to the tooth fairy. She wonders whether she looks more like a beaver or a hippopotamus.

She certainly looks nothing like me, her overweight, white, 50-year-old family physician mother. She is neither tall nor short but has the thin, long legs and arms some school-age girls seem to sprout. She has fine, long, dark brown hair and small, black eyes. Not black eyes from allergic shiners or from wrestling with her older brother (who has coarse black hair and beautiful brown eyes), but black eyes that are all pupil and no iris. That they are black is hard to see, however, unless you look closely. Her eyes really are small and almond shaped and behind her glasses, they are usually half closed. When we stepped off the plane from Seoul with her $81 / 2$ years ago, though, they just looked like ordinary baby eyes surrounded by chubby cheeks and not much hair.

A few off-hand phrases still ring in my memory from the next few months.

This article was externally peer reviewed.

Submitted 10 May 2007; revised 29 June 2007; accepted 2 July 2007.

From the Department of Family Medicine, University of Cincinnati, Cincinnati, OH.

Funding: none.

Conflict of interest: none declared.

Corresponding author: Department of Family Medicine, University of Cincinnati, PO Box 670582, Cincinnati, OH 45267-0582 (E-mail: eldernc@fammed.uc.edu).
- At her 6-month well child visit: "Her red reflex looks really strange. Why don't you take a look, too?" ("Why are you even doing a red reflex on a 6 month old?" is quickly replaced by, "That IS strange. What could it be?")

- At her first ophthalmology visit: "Well, yes, she does have a cataract, but that doesn't bother me nearly as much as the aniridia." (I can figure out the Latin: without irises, but what does it mean? Did I miss that lecture in ophthalmology 20 years ago?)

- From her genetics clinic intake form: "Medical history of the child's natural parents." (What does that make us, unnatural?)

It's been $81 / 2$ interesting years.

- An unexpected special needs child: Our adoption agency inquires, "Do we still want to keep her?"

- Light sensitivity: Little baby sunglasses that spend more time being chewed than worn.

- Poor depth perception: A newly walking toddler feeling the ground with her hand before stepping-is this a step or just a different colored tile?

- Rare genetic disease: Finding connections to anyone with aniridia-our adoption social worker's colleague's next-door-neighbor has a sister across the country who has a daughter with aniridia.

- Low vision: Early eye chart testing with her small voice quietly admitting, "I can't know that one."

She is making it though. Most days, her aniridia is an insignificant part of who she is. She loves school, especially math. She fearlessly climbs the tree with her brother. She practices the piano. She watches TV and plays with her friends and is a Brownie and 
even played T-ball for a couple of years (a perfect designated hitter, power swing, but hated fielding).

She is learning to speak up for herself. "Why do you have to tell everyone about my eyes?" One medic alert bracelet later and now her physician mom doesn't worry about worst-case scenarios like falling off a horse, losing consciousness from a head injury, and some overzealous emergency department doctor stressing over "fixed and dilated pupils."

This year, though, irony crept into her life. She is diagnosed with a central auditory processing disorder and an auditory memory deficit. Standard recommendation: greater dependence on visual learning skills. What an ironic coincidence, I think, my visually impaired daughter diagnosed with an auditory problem. Then I see a new article finding a relationship between auditory processing deficits and the aniridia PAX6 mutation. Maybe it's not irony after all, but her genetic mutation.

Still, after $81 / 2$ years of living with a child with a condition I don't remember ever learning about in medical school, it takes more than this to faze me. I don't remember learning about central auditory processing disorders in medical school, either (did I miss all the important lectures?), but I'm finding out. And although we are still trying to figure out what this will mean for my daughter, I have no doubt that she will again find a way to compensate and succeed.

Her hand often finds its way into mine or onto the hem of my jacket or shirt. It is such a common occurrence, that until recently, I never really gave it much thought. But she really only does it in certain places: walking in a mall crowded with people moving quickly and erratically; stepping out of a building into a bright day; maneuvering through a parking lot with uneven pavement. If you asked my daughter if she was holding me for guidance or support, she would have no idea what you are talking about. But I know inside her are innate survival skills that belie her waiflike appearance.

So I tell her no, she doesn't look like a beaver or a hippopotamus. I tell her she looks like a mighty lion roaring her authority across the savannah. She rolls her eyes at me. She is, after all, almost 9. 